\title{
Investigating the Factors Affecting Depression By Using Structural Equation Modeling
}

\author{
Meryem Firat ${ }^{1^{*}}$ (D), Yalçın Kanbay² ${ }^{\text {(D) }}$, Burcu Demir Gökmen³ ${ }^{3}$, Mehmet Utkan ${ }^{4}$, \\ Ayşe Okanli ${ }^{5}$ (D)
}

\begin{abstract}
The objective of the research was to study the factors affecting depression in general population. Materials and Methods. A total of 1,291 individuals at the age of 15-68 years participated in this cross-sectional study. The Demographic Information Form, the Beck Depression Inventory for Primary Care and the Generalized Anxiety Disorder Scale were used as data collection tools. The data obtained were evaluated in the SPSS 23 package program. Missing data were validated for extreme values, and, then, tested for normality and homogeneity. Testing for the research model was implemented by structural equation modeling using the AMOS program.

Results. The following goodness-of-fit values were determined for the revised model predicting the factors influencing depression: $\chi^{2}=535.62, \chi^{2} / \mathrm{df}=4.74$, the normed fit index $=0.95$, the Tucker-Lewis index $=0.95$, the comparative fit index $=0.96$, the goodness-of-fit index $=0.95$, the adjusted goodness-of-fit index $=0.94$, the root-mean-square error of approximation $=0.05$, the root mean square residual $=0.12$, which were within acceptable limits. According to our model, the generalized anxiety disorder-7 $(t=15.923 ; p<0.001)$, gender $(t=-5.866 ; p<0.001)$, age $(t=-8.193 ; p<0.001)$ and marital status $(t=-6.107 ; p<0.001)$ had a significant effect on depression. However, there was no significant relationship between depression score and educational status, place of residence, family type, and smoking.

Conclusions. In this model of our study, generalized anxiety disorder was found to have the greatest effect on depression, followed by age, marital status, and gender, respectively.

\section{Keywords}

Depression; Generalized Anxiety Disorder; Structural Equation Modeling

${ }^{1}$ Faculty of Health Sciences, Nursing Department, Mental Health and Psychiatric Nursing, Erzincan Binali Yildirim University, Erzincan, Turkey

${ }^{2}$ Faculty of Health Sciences, Nursing Department, Mental Health and Psychiatric Nursing, Artvin Coruh University, Artvin, Turkey

${ }^{3}$ Health High School, Nursing Department, Mental Health and Psychiatric Nursing, Agri Ibrahim Cecen University, Agri, Turkey

${ }^{4}$ Faculty of Health Sciences, Nursing Department, Health Education, Kafkas University, Kars, Turkey

${ }^{5}$ Faculty of Health Sciences, Nursing Department, Mental Health and Psychiatric Nursing, Istanbul Medeniyet University, Istanbul, Turkey

*Corresponding author: meryemfirat@hotmail.com
\end{abstract}

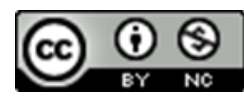

Copyright @Meryem Firat, Yalçın Kanbay, Burcu Demir Gökmen, Mehmet Utkan, Ayşe Okanli, 2021

\section{Problem statement and analysis of the latest research}

Depression is a widespread health problem, affecting individual's life and functionality in all respects, and, eventually, causing socio-economic problems [1]. Depression is an emotional state when an individual feels unhappy and worthless. It is a complex problem presenting itself as feelings of social isolation and apathy, as well as various problems including nutrition, sleep, sexual functions and concentration [2, 3].

According to the "Prevalence of Chronic Illness in Turkey" survey, depression reducing quality of life by preventing productivity, functionality, and happiness has a prevalence of $13.1 \%$ among women, $5 \%$ among men, and $9.3 \%$ in total $[4,5]$. In addition to its high prevalence, depression has a high recurrence rate, it can become chronic and increase suicidality $[6,7]$ and it can also be considered as one of the most common causes of disability due to its effects causing loss of ability at quite high levels [8, 9]. Various factors including female gender, traumatic life events, serious financial problems, genetic predisposition, and dissatisfaction with life can be 
mentioned among the causes of depression [10]. However, depression has been reported to be triggered by the combination of multiple variables, rather than by one single reason [8].

A review of the national literature revealed no recent study on mental health representing the society as a whole for a considerably long period. Especially since 2000s, studies on depression involving different groups such as women, adolescents, and students who are more sensitive and vulnerable than other groups in the society have been carried out $[2,11,12]$. However, a large-scale study representing the whole society has not been conducted, and the factors affecting depression have not been examined.

Therefore, the objective of the research was to investigate the factors influencing depression in general population.

\section{Materials and Methods}

This cross-sectional study was conducted to investigate the factors affecting depression in the general population. The random sampling method was used in the research. Data collection forms, prepared in accordance with the study objective, were entered into our online database. The link to these forms were shared through various applications (WhatsApp, BiP, etc.) with as many people as possible, expecting them to have these forms filled in and return to our database. The forms were shared online, and participants did not meet. Each of the researchers shared data collection forms with an average of 400 people (1,600 people in total). The data collection process was monitored regularly and it was terminated after no new data arrived for about a week. At the end of this process, a total of 1,291 forms were returned.

The Demographic Information Form, the Generalized Anxiety Disorder Scale (GAD-7) and Beck Depression Inventory for Primary Care (BDI-PC) were used as data collection tools.

\section{Demographic Information Form}

It collects information on the sociodemographic characteristics of the participants $[2,8,12]$.

\section{BDI-PC}

The BDI-PC [13], developed by Beck et al. and adapted to Turkish by Aktürk et al., is a measurement tool revealing the presence of depression over the past 15 days [14]. The survey conducts depression screening under seven topics using symptoms of sadness, pessimism, past failure, selfdislike, self-criticalness, loss of interest, and suicidal thoughts or wishes. Each topic contains a four-graded score from 0 to 3. Scoring is obtained by summing up the scores of each topic. On the scale, one can get a maximum of 21 points. Although there is no cut-off score reported, the probability of depression is above $90 \%$ with scores of 4 and above [14].

\section{GAD-7}

It is a 7-item self-reporting scale developed by Spitzer et al. according to the Diagnostic and Statistical Manual of Mental
Disorders, Fourth Edition (DSM-IV-TR) criteria [15]. The items are rated on a 4-point Likert-type scale. It evaluates the generalized anxiety disorder in the past two weeks. It was adapted to Turkish by Konkan et al. and its validity and reliability were proven [16]. The acceptable cut-off value in the Turkish version was calculated as 8 .

\section{Data Analysis}

The study data were analyzed by the SPSS 23 and AMOS 23 package programs. The data obtained were first validated for missing data and extreme values in the SPSS 23 package program, and, then, normality tests and homogeneity tests were conducted. Descriptive statistics of the research were performed using the SPSS 23 package program. Structural Equation Modeling (SEM) was used to determine the factors affecting depression. SEM is a more powerful technique as compared to other analysis methods, since it assumes a causal structure among a set of the latent variables, and those variables can be measured by using observable variables [17]. In fact, SEM is a modelling system, actively involving multivariate statistical analysis methods such as regression, factor analysis and variance (covariance) analysis. This technique includes one or more linear regression equations describing how the internal structures are linked to the external structures [18].

In SEM, detailed explanation of all the parameters associated with the relationships between the variables in the model means constructing the model. There are two main components in SEM: the measurement model and the structural model. SEM analysis should start with the measurement model $[18,19]$. In the measurement model, relationships with non-predefined directions (correlations) among the variables can be calculated by defining the latent variables. In the structural model, however, the direction is determined for each relationship between the latent variables and variables that are not indicative of the latent variable, and some parameters are fixed. In determining the SEM model, all the indicator variables and even error variances in the model must be determined, in addition to the parameters about relationships among the latent variables [20].

Goodness-of-fit indices were used to determine the goodness of fit of the model. In structural equation models, there are different fit indices for assessing the model fit. When interpreting fit statistics, some acceptable limit values are used in determining whether the model will be accepted or not, and it is expected to have no difference between the data observed in the structural equation model and the theoretical data [19]. Goodness-of-fit values serve to determine how consistent the relationships in the model are with the study data.

Among the most commonly used indices, those recommended are the Chi Square $\left(\chi^{2}\right) /$ Degree of Freedom (df) Ratio, the Root-Mean-Square Error of Approximation (RMSEA), the Goodness-of-Fit Index (GFI) and the Adjusted Goodness-of-Fit Index (AGFI). In addition, the indices such as the Standardized Root Mean Square Residual (SRMR), 
the Comparative Fit Index (CFI), the Normed Fit Index (NFI) and the Tucker-Lewis Index (TLI) are commonly used as well.

Although the chi-square-to-degrees of freedom ratio is expected to be no more than 3-4, there are also studies indicating that it can be up to 5. However, other goodness-of-fit values were developed as well, since the chi-square value can be easily affected by the sample size. The RMSEA is a value used to test the hypothesis assuming that the correlation is equally distributed [19]. This value is expected to be less than 0.08 ( $<1$ according to some studies); however, the RMSEA value below 0.05 is recognized as an even better indicator of compatibility [19, 21].

The GFI value indicates that two different models tested in the same sample can be compared. The AGFI value, however, is the adjusted version, considering the complexity of the GFI model. These values are expected to be 0.90 and above [19]. However, according to some reports, the GFI and AGFI values can be acceptable in the interval of 0.80-0.89 [2224]. The SRMR is another criterion for the goodness of fit. The SRMR value is expected to be less than 0.08, as in case of the RMSEA [19].

\section{Results}

The mean age of the sample was $28.6 \pm 10.1$ years; $71.1 \%$ of the group were women; the majority was single $(63 \%)$ and had nuclear family types $(84.8 \%)$. According to the education level, university graduates $(81.8 \%)$ predominated; the overwhelming majority lived in a metropolitan $(43 \%)$ or a city $(32.8 \%)$. In addition, $25.9 \%$ of the group smoked (Table 1).

Table 1. Demographic characteristics of the sample.

\begin{tabular}{llcc}
\hline Variable & Parameter & $\mathrm{n}$ & $\%$ \\
\hline \multirow{2}{*}{ Gender } & Female & 918 & 71.1 \\
& Male & 373 & 28.9 \\
\hline Marital & Single & 813 & 63 \\
Status & Maried & 478 & 37 \\
\hline Family & Nuclear Family & 1,095 & 84.8 \\
Type & Extended Family & 196 & 15.2 \\
\hline \multirow{3}{*}{ Educational } & Primary School Graduate & 24 & 1.9 \\
Level & Middle School Graduate & 23 & 1.8 \\
& High School Graduate & 188 & 14.6 \\
& University graduate & 1,056 & 81.8 \\
\hline \multirow{2}{*}{ Place of } & Village & 81 & 6.3 \\
Residence & Town & 232 & 18 \\
& City & 423 & 32.8 \\
Smoking & Metropolis & 555 & 43 \\
Status & Yes & 956 & 74.1 \\
\hline \multirow{2}{*}{ Age } & Mean (years) & 335 & 25.9 \\
\hline & \multicolumn{2}{c}{ Standard Deviation } \\
& & 10.1 & \\
\hline
\end{tabular}

The first-level single-factor structure of the BDI-PC scale consisting of single dimension and 7 items was tested by discriminant function analysis (DFA). Maximum likelihood estimation method was used due to the normal distribution of the data. Factor loads of all items in the scale ranged between 0.46 and 0.73 . The measurement model for the BDI-PC scale was validated as a result of our data, due to the fit indices obtained in the study. Consequently, the fit indices on the BDI-PC scale were as follows: $\chi^{2}=46.17, \chi^{2} / \mathrm{df}=3.551$, the $\mathrm{NFI}=0.98$, the $\mathrm{TLI}=0.97$, the $\mathrm{CFI}=0.98$, the $\mathrm{GFI}=0.99$, the $\mathrm{AGFI}=0.98$, the RMSEA $=0.04$, and the $\mathrm{RMR}=0.02$. The goodness-of-fit values obtained as a result of the secondlevel DFA indicated that the two-factor model was compatible with the data and within acceptable levels. These results demonstrated that the data obtained in the study were in compliance with the predicted theoretical structure of the Beck-PC scale (Fig. 1).

The structure of the GAD-7 scale, consisting of single dimension and 7 items, was tested with first-level single-factor DFA and maximum likelihood estimation method was used. Factor loads of the scale items ranged from 0.76 to 0.83 , and all the items included in the original scale were included in the analysis and the fit indices of the scale were examined. According to the findings, the fit indices on the GAD-7 scale were as follows: $\chi^{2}=36.23, \chi^{2} / \mathrm{df}=3.294$, the $\mathrm{NFI}=0.99$, the TLI $=0.99$, the CFI $=0.99$, the GFI $=0.99$, the AGFI $=$ 0.98 , the RMSEA $=0.04$, and the RMR $=0.01$. The goodnessof-fit values obtained as a result of the first-level DFA were found to show a perfect fit with the suggested single-factor structure of the model. These findings showed that the data obtained in the study were compatible with the proposed theoretical structure of the GAD-7 scale.

The reliability of the scales used in the study were assessed by Cronbach's alpha. Cronbach's alpha values obtained for the scales were calculated as 0.78 for the BDI-PC scale and 0.92 for the GAB-7 scale. These values showed that the reliability of the scales was within normal range (Table 2).

Table 2. Reliability data regarding the BDI-PC scale and the GAD-7 scale.

\begin{tabular}{lcc}
\hline Scales & $\begin{array}{c}\text { Number } \\
\text { of } \\
\text { items }\end{array}$ & $\begin{array}{c}\text { Internal Consistency } \\
\text { Coefficient } \\
\text { (Cronbach's Alpha) }\end{array}$ \\
\hline Beck-PC Scale & 7 & 0.78 \\
GAB-7 Scale & 7 & 0.92 \\
\hline
\end{tabular}

In order to predict the factors causing depression, the initial structural model was established and the goodness-offit values of this model were examined. The GAD-7 scale mean score, and the variables such as age, gender, marital status, family type, educational status and smoking status were included in the model. The goodness-of-fit values of the model revealed that the values did not provide the minimum goodness-of-fit values required for a valid model $\left(\chi^{2}=1676.41, \chi^{2} / \mathrm{df}=9.11\right.$, the NFI $=0.84$, the $\mathrm{TLI}=0.83$, the CFI $=0.85$, the GFI $=0.89$, the AGFI $=0.86$ the RM- 

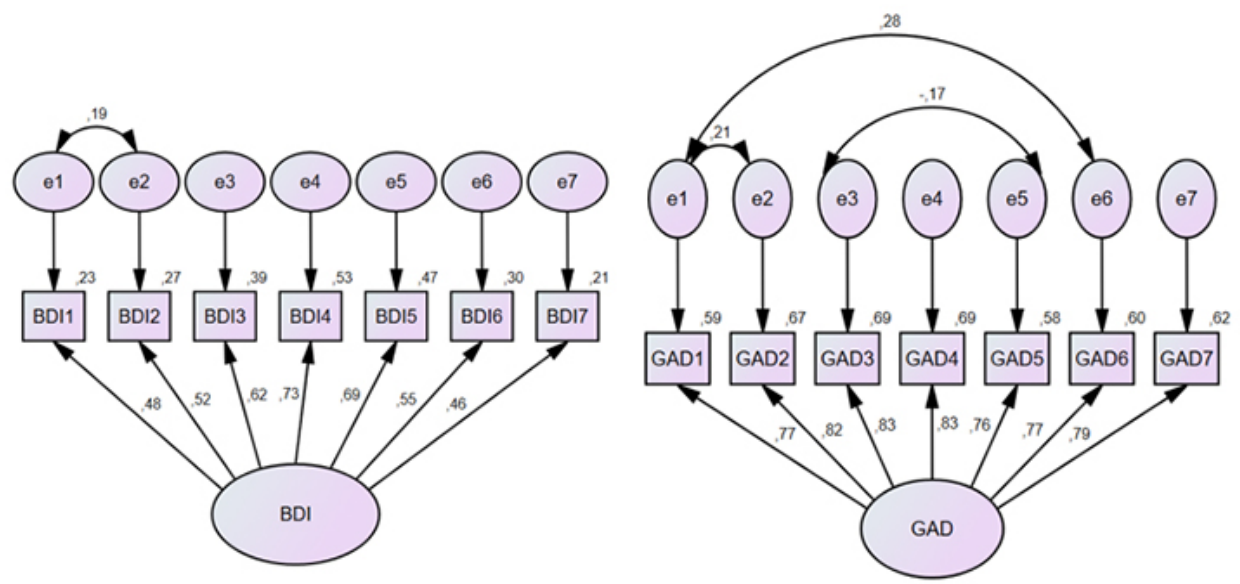

Figure 1. Path diagram of the BDI-PC scale and the GAD-7 scale measurement model.

SEA $=0.08$, the RMR $=0.26$ ) (Fig. 2).

When the standardized regression weights of the variables included in the initial prediction model and the significance of their contribution to the model were examined, the variables of family type, place of residence, educational status and smoking status were found not to show a significant relationship with the model $(\mathrm{p}>0.05)$. Moreover, the goodness-of-fit values of the initial structural model as a whole were not at an acceptable level. For these reasons, the variables of "family type", "place of residence", "educational level" and "smoking status" were excluded from the analysis and a new structural model was created in order to obtain a new model with higher goodness-of-fit values in comparison to the present model or to increase the fit of the model to the dataset (Table 3).

When the revised model predicting the factors affecting depression and the goodness-of-fit values were examined, the goodness-of-fit values were found to be at the desired level $\left(\chi^{2}=535.62, \chi^{2} / \mathrm{df}=4.74\right.$, the NFI $=0.95$, the TLI $=0.95$, the CFI $=0.96$, the GFI $=0.95$, the AGFI $=0.94$, the RM$\mathrm{SEA}=0.05$, the RMR $=0.12$ ) and the design of the model was finalized. The GAD-7 $(\mathrm{t}=15.923 ; \mathrm{p}<0.001)$, gender $(\mathrm{t}=-5.866 ; \mathrm{p}<0.001)$, age $(\mathrm{t}=-8.193 ; \mathrm{p}<0.001)$, and marital status $(\mathrm{t}=-6.107 ; \mathrm{p}<0.001)$ were found to have a significant effect on depression. As regards to the standardized regression coefficients in the model, among those independent variables that were determined to be signficant, the effect of the GAB-7 scale was found to be more significant (0.69) than the other independent variables. The direction of the relationship between the variable "gender" and depression showed that women had a significantly higher level of depression than men. The variable "age", however, was found to be inversely related to depression. According to these data, the level of depression decreased with age. "Marital status", as another variable, had a significant effect on depression as well. It can be said that depression levels were higher in single individuals as compared to married ones (Fig. 3).

\section{Discussion}

In this study examining the factors affecting depression, which is one of the most common and important social challanges, the data obtained were discussed in the light of the literature.

Generalized anxiety disorder has been found to play a great role as one of the triggers of depression. These data were consistent with studies reporting about a significant overlap between anxiety and depression and that depression-anxiety comorbidity was always common [25-27].

Most studies on depression looked at the female-to-male ratio and higher depression scores were found in women as compared to men [28-31]. Moreover, the majority of patients with depression in Turkey were reported to be women (65$70 \%$ ) with higher risk in terms of both dysthymia and major depressive disorder; hence, one in four women had depression [28]. Depression is more common in women in most societies, and it has been attributed to the women's physical and psychological nature. In this study, females were found to have higher risk of depression than men. The way a woman copes with stress, her physical and psychological structure, personality traits and sociocultural status cause women more prone to depression.

Depression risk has been found to decrease with age. In the literature, depression was reported to occur mostly in middle age, and to decrease with age [5, 32]. On the other hand, the decreased risk of depression with increasing age may be interpreted as a natural result of developing more effective ways of dealing with problems with age, as well as a decrease in the occurence of adverse life events and personality maturation over time. Age is considered to be a protective factor against depression.

The single lifestyle has been determined as another risk factor for depression. It can be stated that single individu- 


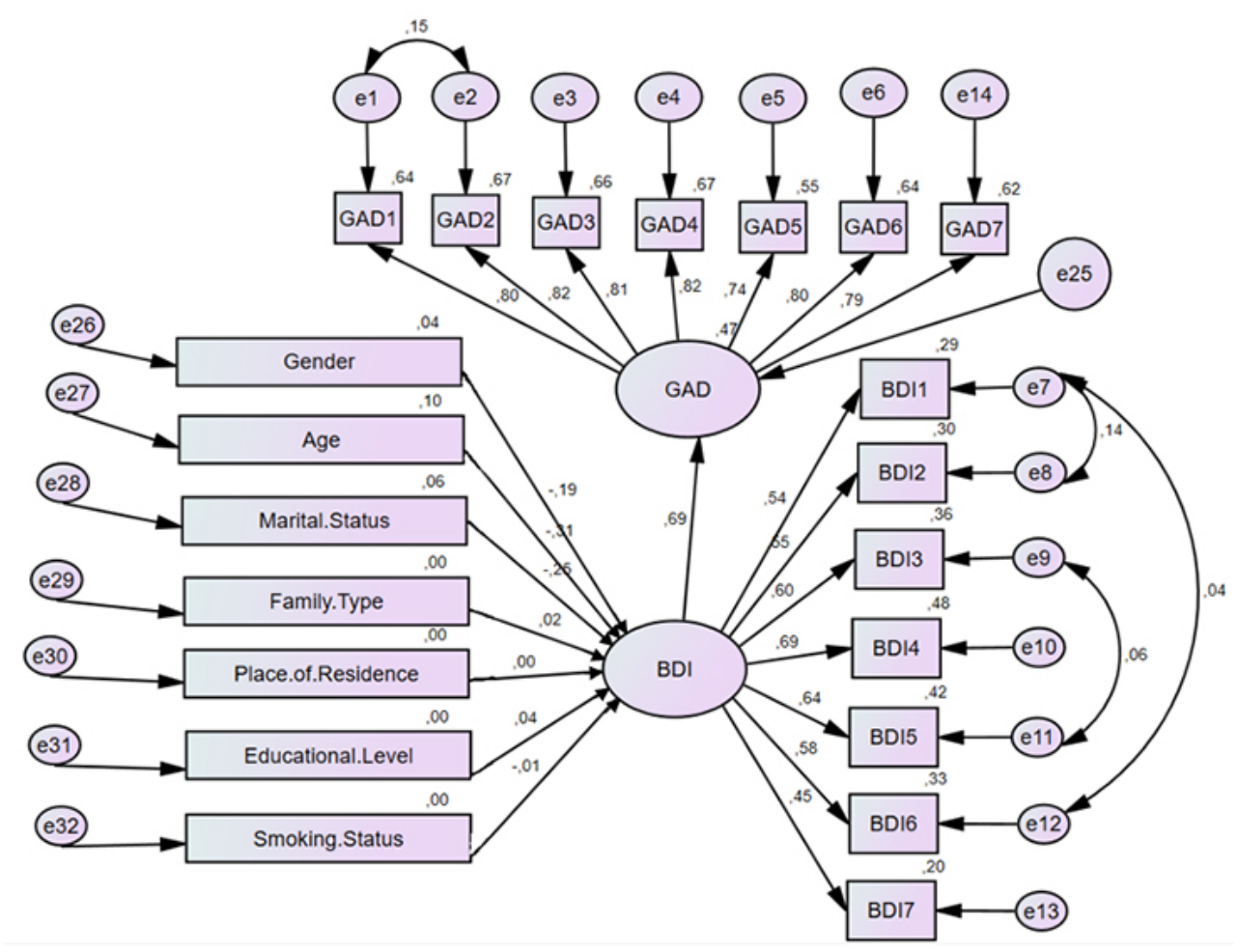

Figure 2. Initial structural model predicting the factors affecting depression.

Table 3. Regression weights of the initial model describing the factors affecting depression.

\begin{tabular}{lcccc}
\hline Parameter & & Latent Structure & $\begin{array}{c}\text { Standardized } \\
\text { Regression Weight }\end{array}$ & Significance \\
\hline GAD-7 & $<-$ & BDI-PC & 0.687 & 0.000 \\
Gender & $<-$ & BDI-PC & -0.193 & 0.000 \\
Age & $<-$ & BDI-PC & -0.310 & 0.000 \\
Marital Status & $<-$ & BDI-PC & -0.248 & 0.000 \\
Family Type & $<-$ & BDI-PC & 0.019 & 0.548 \\
Place of Residence & $<-$ & BDI-PC & 0.001 & 0.969 \\
Educational Status & $<-$ & BDI-PC & 0.040 & 0.199 \\
Smoking Status & $<-$ & BDI-PC & -0.013 & 0.670 \\
\hline
\end{tabular}

als may experience depression more common than married ones. When the risk factors for depression were examined in the literature, the absence of close relations [32] and loneliness [33] were pointed out as the causes of depression. These research data suggested that single individuals have lower rates of social support; they mostly live alone, and, therefore, are at greater risk of depression. There were studies reporting higher levels of depression among single individuals, which was consistent with our findings $[34,35]$. The results of our study are consistent with the literature.

We have found that educational status is not involved in developing depression. Some studies reported that educational status was highly related to depression and individuals with low educational levels were at higher risk of depression [28, 36]. The inconsistency in the results can be attributed to everchanging structure of society and higher levels of education.

Family type and smoking status turned to be the other variables that did not play any role in developing depression as well. Similar results were found in the literature. A number of authors determined that smoking did not affect depression [27, 37]. Similarly, according to some studies, family type and smoking status were not involved in developing depression [38, 39]. After collecting and reviewing the data obtained by the studies examining the risk factors that affect depression, we can state that, our data are quite in conformity with other studies. 


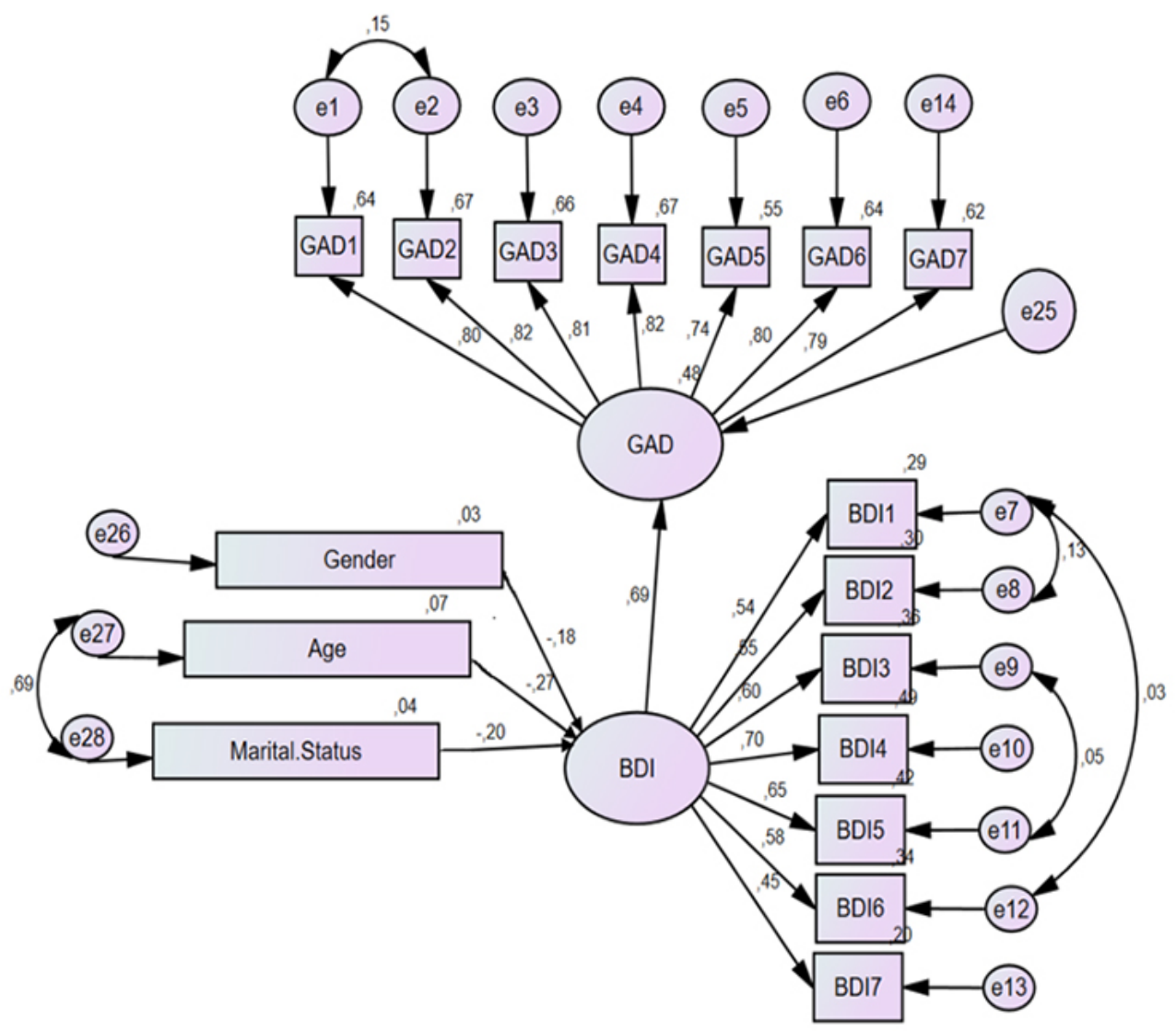

Figure 3. Revised model predicting the factors affecting depression.

\section{Conclusions}

According to the results of our study examining the factors affecting depression, generalized anxiety disorder was found to be a very important factor for developing depression. In addition, the variables such as age, marital status, and gender, respectively, could be considered as important parameters for explaining depression. Young age seemed to be strongly associated with depression; single individuals were more vulnerable to depression than married people. In our sample, women were at higher risk of depression as compared to men.

According to these results, special attention is recommended to be given to women, young people and single ones, who are at high risk of depression.

Considering the significant effect of generalized anxiety disorder on depression, all kinds of measures suppressing generalized anxiety disorder in society may eventually decrease the prevalence of depression. The initiatives for preventing generalized anxiety disorder in society, are therefore, needed to be planned.

\section{Ethical Statement}

Ethical permissions required for the study were obtained from the Artvin Coruh University Scientific Research and Ethical
Review Board (date - 08.05.2020 and session - 2020/7).

\section{Informed Consent}

At the stage of data collection, individual consent was obtained from each participant.

\section{Conflict of Interest}

The authors declare that no conflicts exist.

\section{Financial Disclosure}

The authors declared no financial support.

\section{References}

[1] Cui R. Editorial (Thematic Selection: A Systematic Review of Depression). Current Neuropharmacology [Internet]. 2015 Aug 31;13(4):480-480. Available from: https://doi.org/10.2174/1570159X1304150831123535

[2] Açıkgöz A, Dayı A, Binbay T. Üniversitede okuyan kız öğrencilerde depresyon prevalansı ve 
ilişkili faktörler. Cukurova Medical Journal [Internet]. 2017 Mar 31;43(1):131-140. Available from: https://doi.org/10.17826/cumj.340629

[3] Wang Y-P, Gorenstein C. Psychometric properties of the Beck Depression Inventory-II: a comprehensive review. Revista Brasileira de Psiquiatria [Internet]. 2013 Dec;35(4):416-431. Available from: https://doi.org/10.1590/1516-4446-2012-1048

[4] Ozcan H, Subasi B, Budak B, Celik M, Gurel S, Yildiz M. Relationship between self-esteem, social appearence anxiety, depression and anxiety in adolescent and young adult women. Journal of Mood Disorders [Internet]. 2013;3(3):107. Available from: https://doi.org/10.5455/jmood.20130507015148

[5] Ünal B, Ergör G, Dinç Horosan G et al. Turkey Chronic Diseases and Risk Factors Prevalence Study. Ankara: T.C. Sağlık Bakanlığı Türkiye Halk Sağlığı Kurumu; c2013.

[6] Ahmadi J, Ahmadi N, Soltani F, Bayat F. Gender differences in depression scores of Iranian and german medical students. Iran $\mathbf{J}$ psychiatry Behav Sci [Internet]. 2014;8(4):70-73. Available from: http://www.ncbi.nlm.nih.gov/pubmed/25798177

[7] Reyes-Rodríguez ML, Rivera-Medina CL, CámaraFuentes L, Suárez-Torres A, Bernal G. Depression symptoms and stressful life events among college students in Puerto Rico. Journal of Affective Disorders [Internet]. 2013 Mar;145(3):324-330. Available from: https://doi.org/10.1016/j.jad.2012.08.010

[8] Helvacı Çelik F, Hocaoğlu Ç. Major Depresif Bozukluk' Tanımı, Etyolojisi ve Epidemiyolojisi: Bir Gözden Geçirme. Journal of Contemporary Medicine [Internet]. 2016;6(1). Available from: https://doi.org/10.16899/ctd.91286

[9] Kuyumcu B, Güven M. The Relationship between the Emotional Awareness Expression of Emotion and Psychological Well-Being of Turkish and English University Students. GEFAD/GUJGEF. 2012;32(3):589-607. Available from: http://www.gefad.gazi.edu.tr/tr/download/articlefile/76922

[10] Hür SD, Andsoy II, Şahin AO, Kayhan M, Eren S, Zünbül N, et al. Depressive Symptoms in Karabuk University Health School Students. Journal of Psychiatric Nursing [Internet]. 2014;5(2):72-76. Available from: https://doi.org/10.5505/phd.2014.30075

[11] Binbay T, Direk N, Aker T, Akvardar Y, Alptekin K, Cimilli C, et al. Psychiatric Epidemiology in Turkey: Main Advances in Recent Studies and Future Directions. Turkish Journal of Psychiatry [Internet]. 2014;25(4):264281. Available from: https://doi.org/10.5080/u7463
[12] İskender $\mathrm{H}$, Dokumacioğlu $\mathrm{E}$, Kanbay $\mathrm{Y}$, Kılıç N. Üniversite Öğrencilerinde Sağlıklı Yaşam ve Depresyon Puan Düzeyleri ile İlgili Faktörlerin Belirlenmesi. Acibadem Universitesi Saglik Bilimleri Dergisi [Internet]. 2018;9(4):414-423. Available from: https://doi.org/10.31067/0.2018.64

[13] Beck AT, Guth D, Steer RA, Ball R. Screening for major depression disorders in medical inpatients with the Beck Depression Inventory for Primary Care. Behaviour Research and Therapy [Internet]. 1997 Aug;35(8):785-791. Available from: https://doi.org/10.1016/S00057967(97)00025-9

[14] Aktürk Z, Dağdeviren N, Türe M, Tuglu C. The Reliability and Validity Analysis of the Turkish Version of Beck Depression Inventory for Primary Care. Turkish Soc Fam Pract. 2005;9(3):117-122.

[15] Spitzer RL, Kroenke K, Williams JBW, Löwe B. A Brief Measure for Assessing Generalized Anxiety Disorder. Archives of Internal Medicine [Internet]. 2006 May 22;166(10):1092. Available from: https://doi.org/10.1001/archinte.166.10.1092

[16] Konkan R, Şenormanci Ö, Güçlü O, Aydin E, Z. Sungur M. Yaygın Anksiyete Bozukluğu-7 (YAB-7) Testi Türkçe Uyarlaması, Geçerlik ve Güvenirliği. Nöro Psikiyatri Arşivi [Internet]. 2013 Mar 5;50(1):53-58. Available from: https://doi.org/10.4274/npa.y6308

[17] Y1lmaz V, Çelik HE, Ekiz EH. Investigation of the Factors Affecting Loyalty to Organization through The Structural Equation Modeling: Example from Private and Public Banks. Eskişehir Osmangazi Üniversitesi Sos Bilim Derg. 2006;50(2):171-184.

[18] Sümer N. Structural Equation Models: Basic Concepts and Sample Applications. Türk Psikol Yazıları. 2000;3(6):49-74.

[19] Şimşek ÖF. Introduction to Structural Equation Modeling - Basic Principles and LISREL Applications, First Edition. Ankara: Edison Publisher; c2007.

[20] Eroğlu E. Analysis of Total Quality Management Practices with Structural Equation Modeling. İstanbul: İstanbul Unıversity; 2003.

[21] Fossati A, Maffei C, Acquarini E, Di Ceglie A. Multigroup Confirmatory Component and Factor Analyses of the Italian Version of the Aggression Questionnaire1. European Journal of Psychological Assessment [Internet]. 2003 Mar;19(1):54-65. Available from: https://doi.org/10.1027//1015-5759.19.1.54

[22] Meydan CH, Şeşen H. Structural Equation Modeling AMOS Applications, Second Edition. Ankara: Detay Publisher; c2015. 
[23] Okur E. Environmental Attitude Scale Developed by Structural Equation Modeling. Elem Educ Online. 2012;11(1):85-94.

[24] Doll WJ, Xia W, Torkzadeh G. A Confirmatory Factor Analysis of the End-User Computing Satisfaction Instrument. MIS Quarterly [Internet]. 1994 Dec;18(4):453. Available from: https://doi.org/10.2307/249524

[25] Awadalla S, Davies EB, Glazebrook C. A longitudinal cohort study to explore the relationship between depression, anxiety and academic performance among Emirati university students. BMC Psychiatry [Internet]. 2020 Sep 11;20(1). Available from: https://doi.org/10.1186/s12888-020-02854-Z

[26] Herhaus B, Kersting A, Brähler E, Petrowski K. Depression, anxiety and health status across different BMI classes: A representative study in Germany. Journal of Affective Disorders [Internet]. 2020 Nov;276:45-52. Available from: https://doi.org/10.1016/j.jad.2020.07.020

[27] Woon LS-C, Sidi HB, Ravindran A, Gosse PJ, Mainland RL, Kaunismaa ES, et al. Depression, anxiety, and associated factors in patients with diabetes: evidence from the anxiety, depression, and personality traits in diabetes mellitus (ADAPT-DM) study. BMC Psychiatry [Internet]. 2020 May 12;20(1). Available from: https://doi.org/10.1186/s12888-020-02615-y

[28] Kayahan B, Altıntoprak E, Karabilgin S et al. The Relationship Between Risk Factors and Depression Scores, and Depression Prevalence Among Women Between 1549 Years Age. Anatol J Psychiatry. 2003;4:208-219.

[29] Serpytis P, Navickas P, Lukaviciute L, Navickas A, Aranauskas R, Serpytis R, et al. Gender-Based Differences in Anxiety and Depression Following Acute Myocardial Infarction. Arquivos Brasileiros de Cardiologia [Internet]. 2018. Available from: https://doi.org/10.5935/abc.20180161

[30] Tanhan F. Gender-Based Analysis Of The Relationship Between Teacher's Irrational Beliefs And Depression. Sak Univ J Educ Fac. 2014;28:55-73.

[31] Venkatarao E, Iqbal S, Gupta S. Stress, anxiety \& depression among medical undergraduate students \& their socio-demographic correlates. Indian Journal of Medical Research [Internet]. 2015;141(3):354. Available from: https://doi.org/10.4103/0971-5916.156571

[32] Taycan O, Kutlu L, Çimen S et al. Relation Between Sociodemographic Characteristics Depression and Burnout Levels of Nurse Working in University Hospital. Anadolu Psikiyatr Derg. 2006;7(2):100-108.

[33] Karaoğlu N, Batı AH, Şenol Y et al. Does Medical Education Affect Loneliness, Anxiety, Depression Levels and Empathic Disposition of Medical Students in Turkey? Tıp Eğitimi Dünyası. 2012;34:13-18.

[34] Lök N, Bademli K. Determination of the Relationship Between Physical Activity and Depression in Adult Individuals. Mustafa Kemal Univ J Soc Sci Inst. 2017;14(40):101110.

[35] Zubaroğlu Yanardağ M, Say Şahin D. Yaşlı Bireylerde Sürekli Kayg1 ve Sürekli Depresyon Üzerine Bir İnceleme. Toplum ve Sosyal Hizmet [Internet]. 2019 Jan 23;30(1):37-55. Available from: https://doi.org/10.33417/tsh.516681

[36] Bahar A, Taşdemir S. Anxiety and Depression in Hospitalized Patients at Clinics Medical and Surgical. J Atatürk Univ Sch Nurs. 2008;11(2):9-17.

[37] Deveci ES, Ulutaşdemir N, Açık Y. The Frequency of Signs of Depression and Affecting Factors in the Students of a Health High School. Firat Med J. 2013;18(2):98-102.

[38] Ertem Ü, Yazıcı S. Psychosocial Problems and Depression During Adolescence Period. Fam Community. 2006;8(3):7-12.

[39] Ulas B, Tatlibadem B, Nazik F et al. Depression Prevalence and Related Factors in University Students. Celal Bayar Univ J Heal Sci Inst. 2015;2(3):71-75.

Received: 2020-10-01

Revised: $2020-11-18$

Accepted: 2020-11-27 